\title{
Weight gain after diagnosis of gestational diabetes mellitus and its association with adverse pregnancy outcomes: a cohort study
}

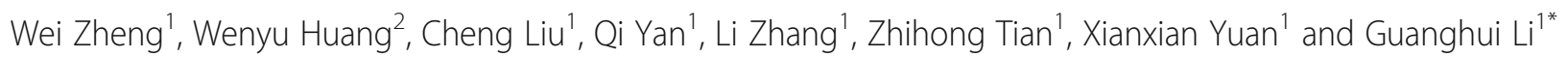

\begin{abstract}
Background: Gestational diabetes mellitus (GDM) and excessive body weight are two key risk factors for adverse perinatal outcomes. However, it is not clear whether restricted gestational weight gain (GWG) is favorable to reduce the risk for adverse pregnancy and neonatal outcomes in women with GDM. Therefore, this study aimed to assess the association of GWG after an oral glucose tolerance test with maternal and neonatal outcomes.

Methods: This prospective cohort study assessed the association of GWG after an oral glucose tolerance test (OGTT) with pregnancy and neonatal outcomes in 3126 women with GDM, adjusted for age, pre-pregnancy body mass index, height, gravidity, parity, adverse history of pregnancy, GWG before OGT, blood glucose level at OGTT and late pregnancy. The outcomes included the prevalence of pregnancy-induced hypertension (PIH) and preeclampsia, large for gestational age (LGA), small for gestational age, macrosomia, low birth weight, preterm birth, and birth by cesarean section. GDM was diagnosed according to the criteria established by the International Association of Diabetes and Pregnancy Study Groups.

Results: GWG after OGTT was positively associated with risk for overall adverse pregnancy outcomes (adjusted odds ratio $[\mathrm{aOR}]=1.72,95 \%$ confidence interval $[\mathrm{Cl}]=1.50-1.97), \mathrm{LGA}(\mathrm{aOR}=1.29,95 \% \mathrm{Cl}=1.13-1.47)$, macrosomia $(\mathrm{aOR}=1.24,95 \% \mathrm{Cl}=1.06-1.46)$ and birth by cesarean section $(\mathrm{aOR}=1.91,95 \% \mathrm{Cl}=1.67-2.19)$ in women with $\mathrm{GDM}$. Further analyses revealed that a combination of excessive GWG before OGT and after OGTT increased the risk of $\mathrm{PIH}$ and preeclampsia, LGA, macrosomia, and birth by cesarean section compared with adequate GWG throughout pregnancy. In contrast, GWG below the Institute of Medicine guideline after OGTT did not increase the risk of adverse perinatal outcomes despite GWG before OGTT.

(Continued on next page)
\end{abstract}

\footnotetext{
*Correspondence: yymzyjs2017@126.com

'Department of Obstetrics, Division of Endocrinology and Metabolism,

Beijing Obstetrics and Gynecology Hospital, Capital Medical University, No

251, Yaojiayuan Road, Chaoyang District, Beijing 100026, China

Full list of author information is available at the end of the article
}

(c) The Author(s). 2021 Open Access This article is licensed under a Creative Commons Attribution 4.0 International License, which permits use, sharing, adaptation, distribution and reproduction in any medium or format, as long as you give appropriate credit to the original author(s) and the source, provide a link to the Creative Commons licence, and indicate if changes were made. The images or other third party material in this article are included in the article's Creative Commons licence, unless indicated otherwise in a credit line to the material. If material is not included in the article's Creative Commons licence and your intended use is not permitted by statutory regulation or exceeds the permitted use, you will need to obtain permission directly from the copyright holder. To view a copy of this licence, visit http://creativecommons.org/licenses/by/4.0/ The Creative Commons Public Domain Dedication waiver (http://creativecommons.org/publicdomain/zero/1.0/) applies to the data made available in this article, unless otherwise stated in a credit line to the data. 
(Continued from previous page)

Conclusion: Excessive GWG after OGTT was associated with an elevated risk of adverse pregnancy outcomes, while insufficient GWG after OGT did not increase the risk of LBW. Restricting GWG after diagnosis of GDM in women with excessive GWG in the first half of pregnancy may be beneficial to prevent PIH and preeclampsia, LGA, macrosomia, and birth by cesarean section.

Keywords: Gestational weight gain, Gestational diabetes mellitus, Oral glucose tolerance test, Pregnancy outcome, Neonatal outcomes

\section{Background}

Gestational diabetes mellitus (GDM) is defined as the onset of or newly recognized glucose intolerance during pregnancy [1]. GDM is reported to affect up to $25 \%$ of pregnant women globally [2], and is associated with a variety of adverse maternal and neonatal outcomes, including hypertensive disorders complicated pregnancy, birth by cesarean section, macrosomia, and large for gestational age (LGA) at birth [3-5].

Excessive gestational weight gain (GWG) is highly prevalent in women with GDM [6, 7]. Large-scale studies and meta-analyses have consistently revealed that excessive GWG is also a critical risk factor for the aforementioned adverse pregnancy outcomes [8, 9]. GDM and excessive body fat are two key factors inducing adverse perinatal outcomes [3, 10, 11]. Kim et al. suggested that excessive GWG contributes the most to the risk of LGA among GDM, pre-pregnancy obesity, and excessive GWG [10].

As such, researchers have conducted a series of studies to assess whether restricting GWG in women with GDM could improve pregnancy outcomes [12, 13]. A meta-analysis by Viecceli et al. suggested that excessive GWG is associated with pharmacological treatment (treatment with antihyperglycaemic agents), hypertensive disorders in pregnancy, birth by cesarean section, LGA, and macrosomic neonates in women with GDM. In contrast, reduced GWG had a protective effect against macrosomia [12]. On the other hand, Wong et al. indicated that restricted GWG does not improve pregnancy results [13]. There has been no consistent conclusion regarding the benefits of weight control in women with GDM.

Furthermore, these studies did not distinguish GWG before and after diagnosis of GDM. It is a global practice that GDM is diagnosed by the oral glucose tolerance test (OGTT) between 24 and 28 weeks of gestation [12, 13]. However, it remains unclear whether weight control in late pregnancy is beneficial. Accelerated fetal growth and development occur in this trimester, and insufficient GWG is associated with an increased risk of low birth weight (LBW) and small for gestational age (SGA) [8]. It is necessary to evaluate the benefits and potential risks of weight control in late pregnancy in women with GDM.

Herein, we investigate the association between GWG after OGTT and maternal and neonatal outcomes adjusting for GWG in the first half of pregnancy using a relatively large dataset, to provide evidence for weight management in women in late pregnancy with GDM.

\section{Methods \\ Study design and participants}

The study participants were from a prospective cohort study in the Beijing Obstetrics and Gynecology Hospital, Capital Medical University. All pregnant women who intended to give birth in this hospital were enrolled in the cohort study at 8-12 weeks of gestation and followed until giving birth. The pregnant women were excluded if their first visit to the hospital were $>13$ weeks of pregnancy or if they are unwilling to participate in the study.

To evaluate the association between GWG after OGTT and maternal and neonatal outcomes in women with GDM, we selected eligible subjects from the recruited pregnant women above. We evaluated all recruited women aged 18-45 who were pregnant with a singleton pregnancy and gave birth in this hospital between January 2014 and December 2017. Women with a pre-existing chronic disease such as heart disease, kidney disease, thyroid disease, type 1 or type 2 diabetes or hypertension were excluded. All participants were required to have their fasting serum glucose levels measured at 8-12 weeks of gestation, and those with fasting serum glucose levels $\geq 6.1 \mathrm{mmol} / \mathrm{L}$ were excluded because they received medical nutrition treatment from early pregnancy. The participants belong to the ethnic Han Chinese group.

We screened a total of 21,075 participants and 2136 were excluded because of twin pregnancy, prepregnancy chronic disease, higher fasting glucose level ( $\geq 6.1 \mathrm{mmol} / \mathrm{L}$ ) or advanced maternal age ( $>45$ years). Of the remaining 18,939 participants, 15,772 participants without GDM were excluded. Further, 91 participants were excluded due to lack of information about baseline characteristics, GWG, or pregnancy outcomes. The remaining 3126 women diagnosed with GDM were used for studying the association of GWG with pregnancy 
and neonatal outcomes. The flow chart of patient inclusion and participation is presented in Fig. 1. This study was approved by the Ethics Committee of the Beijing Obstetrics and Gynecology Hospital.

\section{Measurements}

The participants were followed every month until delivery. Trained research staff reviewed medical records to collect baseline information, metabolic indicators including blood glucose level and blood lipid profiles, and pregnancy and neonatal outcomes. GDM was diagnosed according to the International Association of Diabetes and Pregnancy Study Group (IADPSG) Consensus Panel criteria [1]. The participants were diagnosed with GDM according to the results of a $75 \mathrm{~g}$ OGTT performed between 24 and 28 weeks of gestation under standardised conditions. The diagnosis was made if any of following criteria were met: fasting blood glucose $\geq 5.1 \mathrm{mmol} / \mathrm{L}, 1 \mathrm{~h}$ blood glucose $\geq 10.0$ $\mathrm{mmol} / \mathrm{L}$, or $2 \mathrm{~h}$ blood glucose $\geq 8.5 \mathrm{mmol} / \mathrm{L}$ [1]. Prepregnancy weight was self-reported. The documented weight at the patient's first visit to the hospital (5-6 weeks of gestation) was used when the participants could not remember their pre-pregnancy weight. Participants were classified as underweight, normal weight, overweight, or obese according to prepregnancy body mass index (BMI): < 18.5, 18.5-24.9, $25-29.9$, and $\geq 30 \mathrm{~kg} / \mathrm{m}^{2}$, respectively. Weight at delivery was measured in the hospital. GWG was

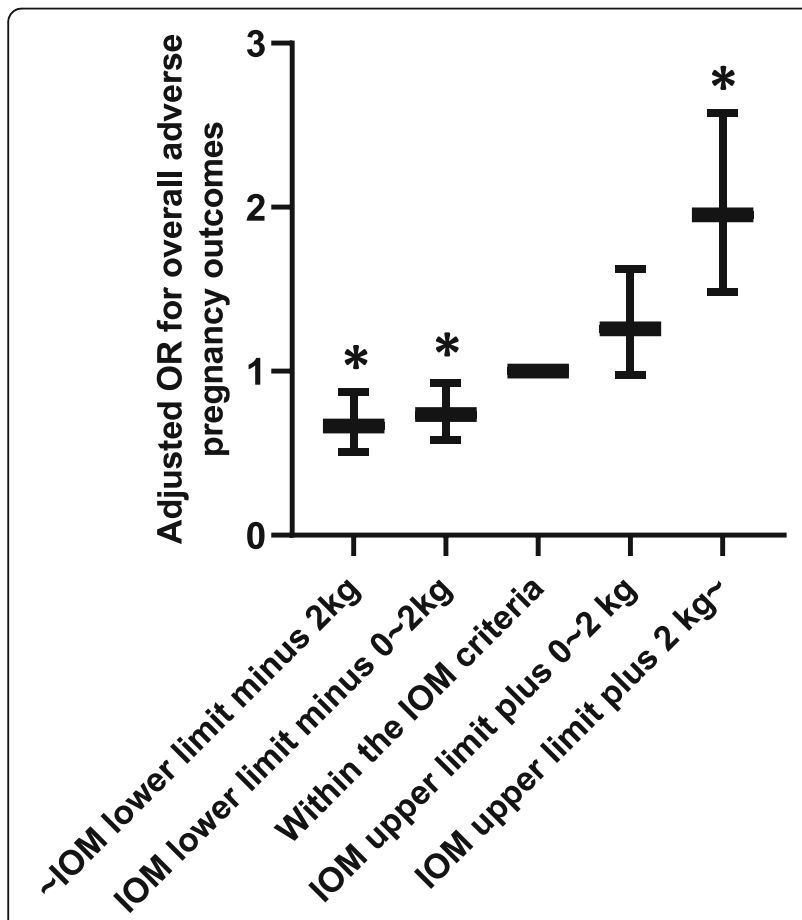

Fig. 1 Flow chart of the selection of study participants calculated as weight at delivery minus pre-pregnancy weight. The appropriate range of GWG was calculated according to the Institute of Medicine (IOM) recommendations [14]. The lower and upper limits of GWG per week were determined as follows: Lower/ upper limit of GWG in the first trimester (i.e., $0.5 \mathrm{~kg}$ and $2 \mathrm{~kg}$ ) + lower/upper GWG rate per week by IOM recommendation $\times$ (gestational week -13 ). GWG at different gestational periods (i.e., GWG before and after OGTT) was classified as insufficient, appropriate, or excessive.

\section{Outcomes}

Maternal and neonatal outcomes included pregnancyinduced hypertension (PIH) and preeclampsia, macrosomia, LBW, LGA, SGA, preterm birth, and birth by cesarean section. PIH was defined as the development of new hypertension after a gestational age of 20 weeks in a previously normotensive woman. Blood pressure was measured at every visit to the hospital (once a month in the second trimester and every 1-2 weeks in the third trimester). Elevated blood pressure was considered systolic blood pressure $\geq 140 \mathrm{mmHg}$ or diastolic blood pressure $\geq 90 \mathrm{mmHg}$ [15]. Preeclampsia was defined as elevated blood pressure after 20 weeks of gestation accompanied by abnormal changes in any organs or systems according to the Diagnosis and Treatment Guidelines for Hypertensive Disorders in Pregnancy in China [16]. Macrosomia and LBW were determined as neonatal birth weight $>4000 \mathrm{~g}$ and $<2500 \mathrm{~g}$, respectively. LGA (neonatal birth weight above the 90th percentile for gestational age) and SGA (neonatal birth weight below the 10th percentile for gestational age) were defined by the international standards proposed by Villar et al. [17]. Gestational age $<37$ weeks was defined as preterm. Birth by cesarean section was classified by indications: previous cesarean section, malpresentation, fetal distress, advanced maternal age ( $>35$ years), cephalopelvic disproportion, etc.. Overall adverse pregnancy outcomes referred to any of the outcomes mentioned above.

\section{Statistical analysis}

We examined the association between a per-unit increase in the GWG level after OGTT and adverse pregnancy and neonatal outcomes in women with GDM using multivariate regression analysis, adjusted for age, pre-pregnancy BMI, height, gravidity, parity, adverse pregnancy history (abortion, stillbirth, fetal death, neonatal death, etc.), GWG before OGTT, blood glucose level at OGTT and late pregnancy. Further, GWG after OGTT was classified as excessive, adequate, or insufficient by IOM criteria. The association of categorized GWG after OGTT with pregnancy and neonatal 
outcomes in women with GDM stratified by GWG before OGTT was evaluated and adjusted for the covariates mentioned above. GWG after OGTT was then divided into five groups by using IOM upper/lower limits and IOM upper/lower limits $\pm 2 \mathrm{~kg}$ as cut-off values. The association of classified GWG after OGTT with overall adverse pregnancy and neonatal outcomes was evaluated and adjusted for the covariates mentioned above. Dietary intervention was not included in the adjusted models because all participants with GDM received a standardized diet intervention (twice a week) after diagnosis. The adjusted factors were selected according to previous reports regarding risk factors for perinatal outcomes. All statistical analyses were conducted in SAS 9.4.

\section{Results}

The basic characteristics, pregnancy, and neonatal outcomes in women with GDM are presented in Table 1. There were no stillbirths after OGTT or neonatal deaths. There was a relatively high prevalence of LGA and macrosomia and a low prevalence of LBW and SGA in the participants. Table 2 shows the proportion of women with insufficient, adequate and excessive GWG.

We then examined the association between a per-unit increase of GWG level after OGTT and adverse pregnancy and neonatal outcomes. GWG after OGTT was positively associated with the risk of overall adverse pregnancy outcomes, LGA, macrosomia, and birth by cesarean section, especially repeated cesarean section and cesarean section due to malpresentation (Table 3).

Table 1 Characteristic of participant women with GDM diagnosed by $75 \mathrm{~g} \mathrm{OGT}$

\begin{tabular}{|c|c|}
\hline & mean $\pm S D$ or $n(\%)$ \\
\hline $\mathrm{N}$ & 3126 \\
\hline Age, year, mean $\pm S D$ & $31.69 \pm 3.81$ \\
\hline \multicolumn{2}{|l|}{ Education level } \\
\hline College or higher, n(\%) & $2225(71.18)$ \\
\hline Up to high school, n(\%) & $901(28.82)$ \\
\hline Gravidity, 1st, n(\%) & $1433(45.84)$ \\
\hline Primiparity, n(\%) & $2462(78.76)$ \\
\hline Adverse pregnancy history, n(\%) & $427(13.66)$ \\
\hline Height, $\mathrm{cm}$, mean $\pm \mathrm{SD}$ & $162.54 \pm 4.75$ \\
\hline Pre-pregnancy weight, $\mathrm{kg}$, mean $\pm \mathrm{SD}$ & $62.35 \pm 12.19$ \\
\hline Pre-pregnancy $\mathrm{BMI}, \mathrm{kg} / \mathrm{m}^{2}$, mean $\pm \mathrm{SD}$ & $23.58 \pm 4.35$ \\
\hline Maternal weight at delivery, $\mathrm{kg}$, mean \pm SD & $75.45 \pm 11.75$ \\
\hline $\mathrm{GWG}, \mathrm{kg}$, mean $\pm \mathrm{SD}$ & $13.10 \pm 5.26$ \\
\hline \multicolumn{2}{|l|}{ Blood glucose level at OGT, $\mathrm{mmol} / \mathrm{L}$, mean $\pm \mathrm{SD}$} \\
\hline $\mathrm{Oh}$ & $5.11 \pm 0.63$ \\
\hline $1 \mathrm{~h}$ & $9.67 \pm 1.71$ \\
\hline $2 \mathrm{~h}$ & $8.05 \pm 1.60$ \\
\hline Gestational weeks of OGT, mean \pm SD & $24.96 \pm 0.94$ \\
\hline Fasting blood glucose level in late pregnancy, mmol/L, mean $\pm S D$ & $4.85 \pm 0.61$ \\
\hline \multicolumn{2}{|l|}{ Pregnancy outcomes } \\
\hline $\mathrm{PIH}$ and preeclampsia, n(\%) & $295(9.44)$ \\
\hline Birth by cesarean section, $\mathrm{n}(\%)$ & $1102(35.25)$ \\
\hline Gestational age at birth, week, mean \pm SD & $38.58 \pm 1.41$ \\
\hline Preterm, n(\%) & $154(4.93)$ \\
\hline Neonatal birth weight, g, mean \pm SD & $3412 \pm 483$ \\
\hline Macrosomia, n(\%) & $313(10.01)$ \\
\hline LBW, n(\%) & $100(3.20)$ \\
\hline LGA, n(\%) & $759(24.28)$ \\
\hline SGA, n(\%) & $50(1.60)$ \\
\hline
\end{tabular}

GDM gestational diabetes mellitus; BMI body mass index; GWG gestational weight gain; OGT oral glucose tolerance test; PIH pregnancy induced pregnancy; $L B W$ low birth weight; $L G A$ large for gestational age; SGA small for gestational age

Adverse pregnancy history refers to history of abortion, stillbirth, fetal death, neonatal death, etc. 
Table 2 Gestational weight gain in women with GDM according to IOM criteria (n(\%))

\begin{tabular}{ll}
\hline & $\mathbf{N}(\%)$ \\
\hline Total GWG & \\
Insufficient GWG & $819(26.20)$ \\
Adequate GWG & $1281(40.98)$ \\
Excessive GWG & $1026(32.82)$ \\
Weight gain before OGTT & \\
Insufficient GWG & $652(20.86)$ \\
Adequate GWG & $1122(35.89)$ \\
Excessive GWG & $1352(43.25)$ \\
Weight gain after OGTT & \\
Insufficient GWG & $1287(41.17)$ \\
Adequate GWG & $729(23.32)$ \\
Excessive GWG & $1110(35.51)$ \\
\hline
\end{tabular}

GDM gestational diabetes mellitus; IOM Institute of Medicine; GWG gestational weight gain; OGTT oral glucose tolerance test

We further evaluated the risk of adverse pregnancy and neonatal outcomes in women with different GWG before and after OGTT. Women with GDM with adequate GWG throughout pregnancy were defined as the control group. As shown in Table 4 and Supplementary Table 1, women with both excessive GWG before and after OGTT showed a higher risk of PIH and

Table 3 Per-Unit Increase of GWG Level after OGTT and Risks of adverse pregnancy and neonatal outcomes in women with GDM

\begin{tabular}{lll}
\hline & aOR (95\% Cl) & $\boldsymbol{p}$-value \\
\hline Overall adverse pregnancy outcomes & $1.72(1.50-1.97)$ & $<0.0001$ \\
PIH and preeclampsia & $1.12(0.96-1.31)$ & 0.1 \\
LGA & $1.29(1.13-1.47)$ & $<0.0001$ \\
SGA & $1.15(0.87-1.51)$ & 0.3 \\
Macrosomia & $1.24(1.06-1.46)$ & 0.006 \\
LBW & $1.05(0.83-1.33)$ & 0.7 \\
Preterm & $1.08(0.90-1.30)$ & 0.4 \\
Birth by cesarean section & $1.91(1.67-2.19)$ & $<0.0001$ \\
Indicators for cesarean section & & \\
$\quad$ Previous cesarean section & $1.22(1.03-1.44)$ & 0.02 \\
Malpresentations & $1.28(1.04-1.57)$ & 0.02 \\
Fetal distress & $1.06(0.81-1.39)$ & 0.6 \\
Advanced maternal age (> 35 years) & $1.12(0.90-1.38)$ & 0.3 \\
Cephalopelvic disproportion & $1.11(0.84-1.45)$ & 0.5 \\
\hline
\end{tabular}

Adjusted for age, gravidity, parity, PPBMI, height, adverse pregnancy history, GWG before OGT, blood glucose levels at OGT and late pregnancy Overall adverse pregnancy outcomes referred to prevalence of any adverse pregnancy outcome below

GWG gestational weight gain; OGTT oral glucose tolerance test; GDM gestational diabetes mellitus; $P I H$ pregnancy induced pregnancy; $L B W$ low birth weight; LGA large for gestational age; SGA small for gestational age; IOM Institute of Medicine; PPBMI pre-pregnancy body mass index preeclampsia, LGA, macrosomia, and birth by cesarean section, especially repeated cesarean section, cesarean section due to malpresentation and advanced maternal age $(p<0.05)$ compared with women with adequate GWG throughout pregnancy. It is notable that women with excessive GWG before OGTT and adequate GWG after OGTT also showed a higher risk of PIH and preeclampsia. On the other hand, lower GWG in late pregnancy did not increase LBW or SGA risk regardless of GWG in the first half of pregnancy. Further, women with lower weight gain than the control group after OGTT showed a reduced LGA risk.

We also divided participants into five groups according to GWG after OGTT and compared the risk of adverse pregnancy outcomes among the groups. As shown in Fig. 2, weight gain more than the IOM criteria plus 2 $\mathrm{kg}$ in late pregnancy was associated with an increased risk of adverse pregnancy outcomes, while GWG less than the IOM criteria was related to a lower risk of overall adverse pregnancy outcomes.

\section{Discussion}

We evaluated the association of GWG after OGTT with maternal and neonatal outcomes in women with GDM. GWG in late pregnancy was positively associated with the risk of LGA, macrosomia, and birth by cesarean section after adjustment for pre-pregnancy BMI, GWG before OGTT, and the glucose level at OGTT and late pregnancy, etc. Furthermore, in women with excessive GWG before OGTT, both adequate and excessive GWG in late pregnancy increased the risk of adverse pregnancy and neonatal outcomes. Of note, GWG lower than the IOM guidelines after GDM diagnosis was not associated with adverse perinatal outcomes, regardless of GWG before OGTT.

The appropriate GWG for women with GDM has been a complicated topic. Most studies evaluating GWG in women with GDM did not classify GWG before and after GDM diagnosis. Some researchers have declared that restricting GWG in women with GDM may benefit pregnancy outcomes. A metaanalysis by Viecceli et al. [12] suggested that excessive GWG in women with GDM is associated with an increased risk of hypertensive disorders in pregnancy, birth by cesarean section, LGA and macrosomia at birth relative to women with GDM without excessive GWG. They suggested that restricted GWG might be beneficial for women with GDM, whereas other researchers came to different conclusions. Some studies did not find an association between GWG and neonatal birth weight in underweight or normal-weight women with GDM [18, 19]. Wong et al. [13] suggested that applying a more restrictive GWG target than the IOM criteria did not improve pregnancy 
Table 4 GWG after OGTT in women with GDM classified by IOM criteria and risk of adverse pregnancy outcomes (aOR (95\% CI))

\begin{tabular}{|c|c|c|c|c|c|c|c|}
\hline & $\begin{array}{l}\text { PIH and } \\
\text { preeclampsia }\end{array}$ & LGA & SGA & Macrosomia & LBW & Preterm & $\begin{array}{l}\text { Cesarean } \\
\text { section }\end{array}$ \\
\hline \multicolumn{8}{|l|}{ Insufficient GWG before OGTT } \\
\hline $\begin{array}{l}\text { Lower than IOM criteria after OGTT, } \\
n=196\end{array}$ & $1.95(0.92-4.14)$ & $\begin{array}{l}0.52(0.32- \\
0.82)\end{array}$ & $\begin{array}{l}1.35(0.44- \\
4.18)\end{array}$ & $\begin{array}{l}0.85(0.42- \\
1.73)\end{array}$ & $\begin{array}{l}1.49(0.56- \\
3.98)\end{array}$ & $\begin{array}{l}1.21(0.48- \\
3.07)\end{array}$ & $\begin{array}{l}1.43(0.94- \\
2.17)\end{array}$ \\
\hline $\begin{array}{l}\text { Within the IOM criteria after OGT, } \\
n=131\end{array}$ & $1.47(0.58-3.75)$ & $\begin{array}{l}0.37(0.20- \\
0.68)\end{array}$ & $\begin{array}{l}2.93(0.99- \\
8.72)\end{array}$ & $\begin{array}{l}0.18(0.04- \\
0.80)\end{array}$ & $\begin{array}{l}1.78(0.58- \\
5.43)\end{array}$ & $\begin{array}{l}1.71(0.60- \\
4.86)\end{array}$ & $\begin{array}{l}1.13(0.68- \\
1.88)\end{array}$ \\
\hline $\begin{array}{l}\text { Higher than IOM criteria after } \\
\text { OGTT, } n=182\end{array}$ & $1.79(0.84-3.81)$ & $\begin{array}{l}0.74(0.46- \\
1.18)\end{array}$ & $\begin{array}{l}1.18(0.32- \\
4.44)\end{array}$ & $\begin{array}{l}0.77(0.37- \\
1.58)\end{array}$ & $\begin{array}{l}1.52(0.52- \\
4.40)\end{array}$ & $\begin{array}{l}1.44(0.55- \\
3.77)\end{array}$ & $\begin{array}{l}1.94(1.25- \\
3.01)\end{array}$ \\
\hline \multicolumn{8}{|l|}{ Adequate GWG before OGTT } \\
\hline $\begin{array}{l}\text { Lower than IOM criteria after OGTT, } \\
n=529\end{array}$ & $1.62(0.78-3.37)$ & $\begin{array}{l}0.61(0.41- \\
0.91)\end{array}$ & $\begin{array}{l}0.38(0.11- \\
1.39)\end{array}$ & $\begin{array}{l}0.43(0.20- \\
0.89)\end{array}$ & $\begin{array}{l}0.97(0.38- \\
2.51)\end{array}$ & $\begin{array}{l}1.49(0.65- \\
3.45)\end{array}$ & $\begin{array}{l}1.10(0.75- \\
1.61)\end{array}$ \\
\hline $\begin{array}{l}\text { Within the IOM criteria after OGTT, } \\
n=303\end{array}$ & 1 & 1 & 1 & 1 & 1 & 1 & 1 \\
\hline $\begin{array}{l}\text { Higher than IOM criteria after } \\
\text { OGTT, } n=305\end{array}$ & $1.87(0.91-3.85)$ & $\begin{array}{l}0.80(0.53- \\
1.21)\end{array}$ & $\begin{array}{l}0.57(0.14- \\
2.34)\end{array}$ & $\begin{array}{l}0.99(0.53- \\
1.88)\end{array}$ & $\begin{array}{l}0.87(0.30- \\
2.58)\end{array}$ & $\begin{array}{l}0.85(0.32- \\
2.23)\end{array}$ & $\begin{array}{l}2.38(1.60- \\
3.55)\end{array}$ \\
\hline \multicolumn{8}{|l|}{ Excessive GWG before OGTT } \\
\hline $\begin{array}{l}\text { Lower than IOM criteria after OGT, } \\
n=690\end{array}$ & $1.11(0.52-2.36)$ & $\begin{array}{l}0.95(0.65- \\
1.39)\end{array}$ & $\begin{array}{l}0.57(0.18- \\
1.81)\end{array}$ & $\begin{array}{l}1.03(0.56- \\
1.92)\end{array}$ & $\begin{array}{l}0.37(0.12- \\
1.18)\end{array}$ & $\begin{array}{l}0.74(0.29- \\
1.85)\end{array}$ & $\begin{array}{l}1.20(0.82- \\
1.75)\end{array}$ \\
\hline $\begin{array}{l}\text { Within the IOM criteria after OGTT, } \\
n=353\end{array}$ & $2.34(1.10-4.99)$ & $\begin{array}{l}1.28(0.84- \\
1.93)\end{array}$ & $\begin{array}{l}0.36(0.07- \\
1.82)\end{array}$ & $\begin{array}{l}1.64(0.86- \\
3.10)\end{array}$ & $\begin{array}{l}0.42(0.11- \\
1.65)\end{array}$ & $\begin{array}{l}0.55(0.18- \\
1.74)\end{array}$ & $\begin{array}{l}1.44(0.94- \\
2.19)\end{array}$ \\
\hline $\begin{array}{l}\text { Higher than IOM criteria after } \\
\text { OGTT, } n=546\end{array}$ & $2.33(1.18-4.61)$ & $\begin{array}{l}1.63(1.13- \\
2.34)\end{array}$ & $\begin{array}{l}0.74(0.23- \\
2.38)\end{array}$ & $\begin{array}{l}2.54(1.45- \\
4.42)\end{array}$ & $\begin{array}{l}0.72(0.26- \\
2.00)\end{array}$ & $\begin{array}{l}0.83(0.34- \\
2.02)\end{array}$ & $\begin{array}{l}3.52(2.42- \\
5.10)\end{array}$ \\
\hline
\end{tabular}

Adjusted for gravidity, parity, PPBMI, height, adverse pregnancy history, blood glucose levels at OGTT and late pregnancy

GWG gestational weight gain; OGT oral glucose tolerance test; $a O R$ adjusted odds ratio; $C l$ confidence interval; GDM gestational diabetes mellitus; $P I H$ pregnancy induced pregnancy; LBW low birth weight; LGA large for gestational age; SGA small for gestational age; IOM Institute of Medicine; PPBMI pre-pregnancy body mass index

outcomes in women with GDM. Cheng et al. [20] found that women with GDM with GWG below the guidelines were more likely to have SGA neonates.

Early- and mid-pregnancy GWG has been consistently confirmed to influence maternal and neonatal outcomes [6, 21-23], whereas evidence is limited regarding GWG after GDM diagnosis. The last trimester is a critical period for fetal growth and development, and fetal growth contributes substantially to GWG during this period [24, 25]. Harper et al. [26] indicated that excessive GWG in late pregnancy increases the risk of preeclampsia, birth by cesarean section, macrosomia, and LGA and does not decrease the rate of SGA or preterm birth. However, they did not consider GWG before OGTT.

In this study, we found that GWG lower than the value specified by the IOM criteria did not increase the risk of SGA or LBW, regardless of GWG in the first half of pregnancy. On the other hand, in women with excessive GWG before OGTT, higher GWG after GDM diagnosis increased the risk of adverse pregnancy outcomes. These findings collectively suggest that restricting GWG after diagnosis of GDM may be advantageous, especially in women with excessive GWG in the first half of pregnancy. One possible explanation for the above results is that hyperglycemia per se has positively associated with neonatal weight [5]. Placental glucose, amino acid, and lipid transport are enhanced in women with GDM than women without GDM; this phenomenon would accelerate fetal growth [27, 28]. The expression of glucose transporter-1 (GLUT1) was higher in hyperglycemic women than controls; this protein is a critical regulator for fetal glucose uptake [28]. Placental amino acid transport is also enhanced due to activation of the nutrient sensor mammalian target of rapamycin (mTOR) [29]. Moreover, women with GDM show higher circulating lipid levels. The excess supply of lipids may contribute to increased placental transport and accelerated fetal growth [30].

We collected information from a relatively large group of women with GDM, which enabled us to conduct analyses by dividing the participants into nine groups according to GWG before and after an OGTT. In practice, women with GDM generally receive dietary intervention and weight management after an OGTT. When nutritionists first meet and provide individual guidance to women who have been newly diagnosed with GDM based on OGTT results between 24 and 28 weeks of gestation, it is vital to set a goal in consideration of GWG in the first half of pregnancy. This study provided 


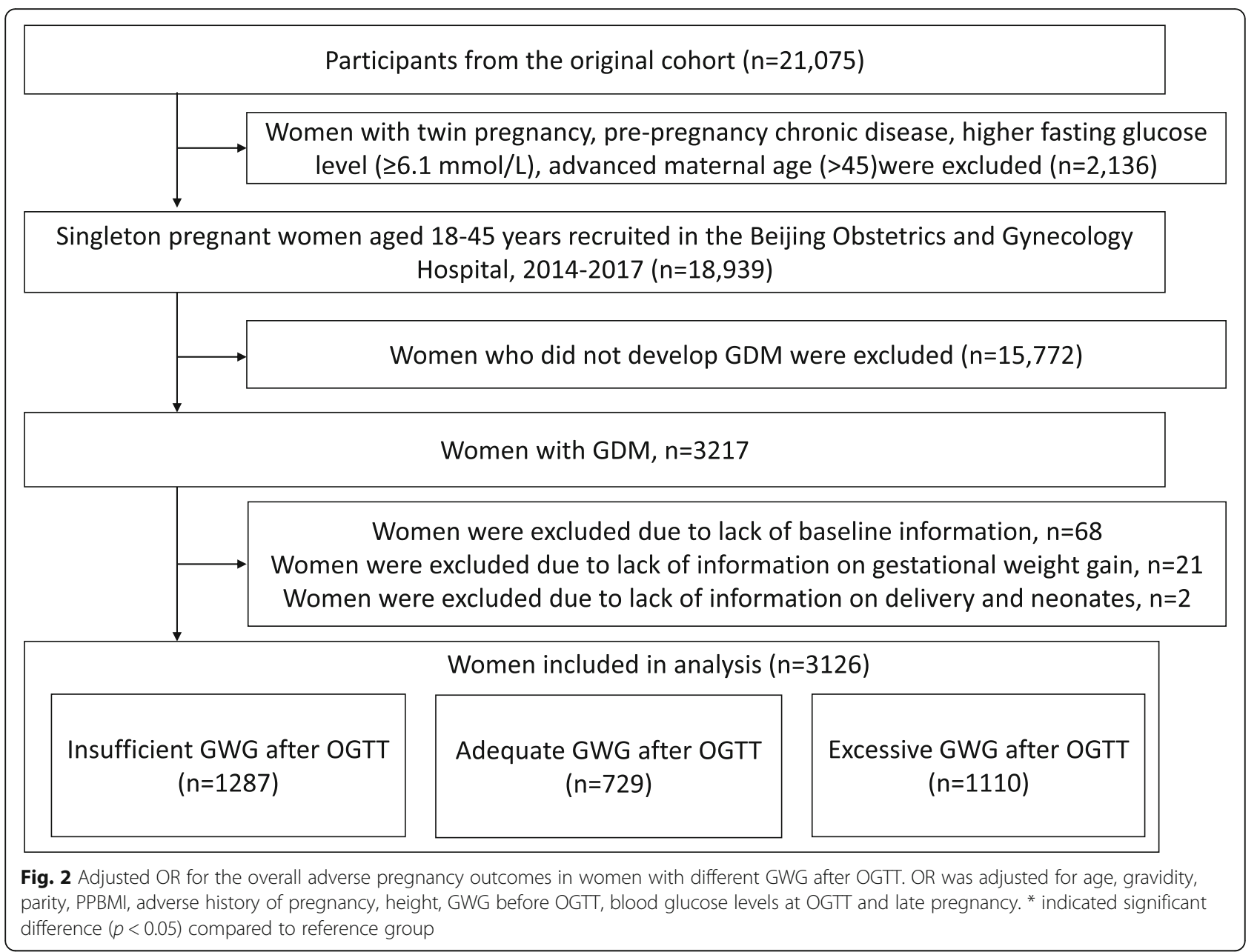

evidence for GWG management after an OGTT in women with GDM. The results suggest that the focus of weight management should be the prevention of LGA, macrosomia, PIH and preeclampsia, and birth by cesarean section. Avoiding excessive GWG could be helpful in the prevention of these pregnancy outcomes.

This study had some limitations. Recall bias may exist because the pre-pregnancy weight was self-reported. In addition, although we suggest that restricting GWG after diagnosis of GDM may be beneficial, there is still limited evidence regarding recommendations for the appropriate GWG range. Further, insulin treatment information, a potential confounder when evaluating pregnancy outcomes, was not available in this study. Other factors such as socioeconomic status and secondary smoking were also unavailable and might confound the results. Last but not least, although the participants were required to meet with the diabetes physicians regularly, they may not have complied with the advice from physicians and gained more or less weight than recommended. We are unaware whether their behaviors affected pregnancy and neonatal outcomes beyond weight gain. Therefore, more studies that consider these unadjusted confounders might further clarify the association between GWG and perinatal outcomes.

\section{Conclusion}

In summary, we found that excessive GWG after diagnosis of GDM was associated with an elevated risk of adverse pregnancy and neonatal outcomes, while insufficient GWG did not increase the risk of SGA or LBW, regardless of GWG before OGTT. Avoiding excessive GWG is more important in women with GDM with adequate or excessive GWG in the first half of pregnancy. Restricting GWG after OGTT may have led to better pregnancy outcomes.

\section{Abbreviations}

GDM: Gestational diabetes; GWG: Gestational weight gain; OGTT: Oral glucose tolerance test; IOM: Institute of Medicine; PIH: Pregnancy induced hypertension; LGA: Large for gestational age; LBW: Low birth weight; SGA: Small for gestational age; BMI: Body mass index; PPBMI: Pre-pregnancy body mass index; IADPSG: International Association of Diabetes and

Pregnancy Study Group 


\section{Supplementary Information}

The online version contains supplementary material available at https://doi. org/10.1186/s12884-021-03690-z.

Additional file 1: Supplementary Table S1. GWG after OGTT in women with GDM classified by IOM criteria and risk of types of Cesarean section $(\mathrm{aOR}(95 \% \mathrm{Cl}))$

\section{Acknowledgements}

We thank the participants for their cooperation and the medical staff for their work on information collection.

\section{Authors' contributions}

WZ conducted the population study, analyzed and interpreted the data, and drafted the manuscript. WH participated in data analysis, interpretation, and draft revision. $\mathrm{CL}$ and QY participated in data collection and results interpretation. $L Z, Z T$ and $X Y$ assisted with data collection and analysis. GL designed the study and critically revised the manuscript. All authors read and approved the final manuscript.

\section{Funding}

Capital's Funds for Health Improvement and Research (CFH 2018-2-2112) supported data collection, dataset management and statistical analysis. National Key Research and Development Program (2016YFC1000304) and National Natural Science Foundation of China (81671477) supported study participants recruitment and follow up. Beijing Natural Science Foundation (S160001) supported information collection and follow up.

\section{Availability of data and materials}

The datasets and code used and/or analyzed during the current study are available from the corresponding author on reasonable request.

\section{Declarations}

\section{Ethics approval and consent to participate}

This study was approved by the Ethics Committee of Beijing Obstetrics and Gynecology Hospital. Written informed consents were obtained from all study participants.

\section{Consent for publication}

Not applicable.

\section{Competing interests}

The authors declare no conflict of interest.

\section{Author details}

'Department of Obstetrics, Division of Endocrinology and Metabolism, Beijing Obstetrics and Gynecology Hospital, Capital Medical University, No 251, Yaojiayuan Road, Chaoyang District, Beijing 100026, China. ${ }^{2}$ Division of Endocrinology, Metabolism and Molecular Medicine, Northwestern University Feinberg School of Medicine, Chicago, USA.

\section{Received: 26 April 2020 Accepted: 2 March 2021}

Published online: 17 March 2021

\section{References}

1. International Association of Diabetes Pregnancy Study Groups Consensus Panel, Metzger BE, Gabbe SG, Persson B, Buchanan TA, Catalano PA, Damm P, Dyer AR, Leiva A, Hod M, et al. International association of diabetes and pregnancy study groups recommendations on the diagnosis and classification of hyperglycemia in pregnancy. Diabetes Care. 2010:33(3):676-82.

2. Zhu Y, Zhang C. Prevalence of gestational diabetes and risk of progression to type 2 diabetes: a global perspective. Curr Diab Rep. 2016;16(1):7.

3. Gillman MW, Rifasshiman S, Berkey CS, Field AE, Colditz GA. Maternal gestational diabetes, birth weight, and adolescent obesity. Pediatrics. 2003; 111(3):e221.

4. Wendland EM, Torloni MR, Falavigna M, Trujillo J, Dode MA, Campos MA, Duncan BB, Schmidt MI. Gestational diabetes and pregnancy outcomes--a systematic review of the World Health Organization $(\mathrm{WHO})$ and the
International Association of Diabetes in Pregnancy Study Groups (IADPSG) diagnostic criteria. BMC Pregnancy Childbirth. 2012;12:23.

5. HAPO Study Cooperative Research Group, Metzger BE, Lowe LP, Dyer AR, Trimble ER, Chaovarindr U, Coustan DR, Hadden DR, McCance DR, Hod M, Mclntyre HD, et al. Hyperglycemia and adverse pregnancy outcomes. N Engl J Med. 2008;358(19):1991-2002.

6. Carreno CA, Clifton RG, Hauth JC, Myatt L, Roberts JM, Spong CY, Varner MW, Thorp JM Jr, Mercer BM, Peaceman AM, et al. Excessive early gestational weight gain and risk of gestational diabetes mellitus in nulliparous women. Obstet Gynecol. 2012;119(6):1227-33.

7. Hedderson MM, Gunderson EP, Ferrara A. Gestational weight gain and risk of gestational diabetes mellitus. Obstet Gynecol. 2010;115(3):597-604.

8. Goldstein RF, Abell SK, Ranasinha S, Misso M, Boyle JA, Black MH, Li N, Hu G, Corrado F, Rode L, et al. Association of Gestational Weight Gain with Maternal and Infant Outcomes: a systematic review and meta-analysis. Jama. 2017;317(21):2207-25.

9. Liu Y, Dai W, Dai X, Li Z. Prepregnancy body mass index and gestational weight gain with the outcome of pregnancy: a 13-year study of 292,568 cases in China. Arch Gynecol Obstet. 2012;286(4):905-11.

10. Kim SY, Sharma AJ, Sappenfield W, Wilson HG, Salihu HM. Association of maternal body mass index, excessive weight gain, and gestational diabetes mellitus with large-for-gestational-age births. Obstet Gynecol. 2014;123(4): 737-44

11. Nehring I, Schmoll S, Beyerlein A, Hauner H, von Kries R. Gestational weight gain and long-term postpartum weight retention: a meta-analysis. Am J Clin Nutr. 2011;94(5):1225-31.

12. Viecceli C, Remonti LR, Hirakata VN, Mastella LS, Gnielka V, Oppermann ML, Silveiro SP, Reichelt AJ. Weight gain adequacy and pregnancy outcomes in gestational diabetes: a meta-analysis. Obes Rev. 2017;18(5):567-80.

13. Wong T, Barnes RA, Ross GP, Cheung NW, Flack JR. Are the Institute of Medicine weight gain targets applicable in women with gestational diabetes mellitus? Diabetologia. 2017;60(3):416-23.

14. Rasmussen KM, Yaktine AK, Rasmussen KM, Yaktine AK. Weight gain during pregnancy: reexamining the guidelines: National Academies Press; 2009.

15. Arulkumaran N, Lightstone L. Severe pre-eclampsia and hypertensive crises. Best Pract Res Clin Obstetr Gynaecology. 2013;27(6):877-84

16. Hypertensive Disorders in Pregnancy Subgroup, Chinese Society of Obstetrics and Gynecology, Chinese Medical Association. Diagnosis and treatment guideline of hypertensive disorders in pregnancy (2015). Chin J Obstetr Gynecol. 2015;50(10):721-8.

17. Villar J, Cheikh Ismail L, Victora CG, Ohuma EO, Bertino E, Altman DG, Lambert A, Papageorghiou AT, Carvalho M, Jaffer YA, et al. International standards for newborn weight, length, and head circumference by gestational age and sex: the newborn cross-sectional study of the INTE RGROWTH-21st project. Lancet. 2014;384(9946):857-68.

18. Horosz E, Bomba-Opon DA, Szymanska M, Wielgos M. Maternal weight gain in women with gestational diabetes mellitus. J Perinat Med. 2013; 41(5):523-8

19. Berggren EK, Stuebe AM, Boggess KA. Excess maternal weight gain and large for gestational age risk among women with gestational diabetes. Am J Perinatol. 2015;32(3):251-6.

20. Cheng YW, Chung JH, Kurbisch-Block I, Inturrisi M, Shafer S, Caughey AB. Gestational weight gain and gestational diabetes mellitus: perinatal outcomes. Obstet Gynecol. 2008;112(5):1015-22.

21. Retnakaran R, Wen SW, Tan H, Zhou S, Ye C, Shen M, Smith GN, Walker MC. Association of Timing of weight gain in pregnancy with infant birth weight. JAMA Pediatr. 2018;172(2):136-42.

22. Cho EH, Hur J, Lee KJ. Early gestational weight gain rate and adverse pregnancy outcomes in Korean women. PLoS One. 2015;10(10):e0140376.

23. Davenport MH, Ruchat S, Giroux I, Sopper MM, Mottola MF. Timing of excessive pregnancy-related weight gain and offspring adiposity at birth. Obstet Gynecol. 2013;122(1):255-61.

24. Durie DE, Thornburg LL, Glantz JC. Effect of second-trimester and thirdtrimester rate of gestational weight gain on maternal and neonatal outcomes. Obstet Gynecol. 2011;118(3):569.

25. Gaillard R, Steegers EA, Franco OH, Hofman A, Jaddoe WW. Maternal weight gain in different periods of pregnancy and childhood cardio-metabolic outcomes. The Generation R Study. Int J Obes. 2014;39(4):677.

26. Harper LM, Tita A, Biggio JR. The Institute of Medicine Guidelines for gestational weight gain after a diagnosis of gestational diabetes and pregnancy outcomes. Am J Perinatol. 2015;32(3):239-46. 
27. Jansson T, Ekstrand $Y$, Björn C, Wennergren M, Powell TL. Alterations in the activity of placental amino acid transporters in pregnancies complicated by diabetes. Diabetes. 2002;51(7):2214-9.

28. Castillo-Castrejon M, Powell TL. Placental nutrient transport in gestational diabetic pregnancies. Front Endocrinol (Lausanne). 2017;8:306.

29. Jansson N, Rosario FJ, Gaccioli F, Lager S, Jones HN, Roos S, Jansson T, Powell TL. Activation of placental mTOR signaling and amino acid transporters in obese women giving birth to large babies. J Clin Endocrinol Metab. 2013;98(1):105-13.

30. Schaefer-Graf UM, Graf K, Kulbacka I, Kjos SL, Dudenhausen J, Vetter K, Herrera E. Maternal lipids as strong determinants of fetal environment and growth in pregnancies with gestational diabetes mellitus. Diabetes Care. 2008;31(9):1858-63.

\section{Publisher's Note}

Springer Nature remains neutral with regard to jurisdictional claims in published maps and institutional affiliations.

Ready to submit your research? Choose BMC and benefit from:

- fast, convenient online submission

- thorough peer review by experienced researchers in your field

- rapid publication on acceptance

- support for research data, including large and complex data types

- gold Open Access which fosters wider collaboration and increased citations

- maximum visibility for your research: over $100 \mathrm{M}$ website views per year

At $B M C$, research is always in progress.

Learn more biomedcentral.com/submissions 